\title{
BMJ Open Factors associated with the awareness of vaginal fistula among women of reproductive age: findings from the 2018 Nigerian demographic health cross- sectional survey
}

\author{
Imran O Morhason-Bello (D) , ${ }^{1,2,3}$ Yusuf Olushola Kareem, ${ }^{4}$ \\ Rukiyat A Abdus-Salam, ${ }^{1}$ Oluwasomidoyin O Bello, ${ }^{1}$ Olatunji O Lawal, ${ }^{1}$ \\ Fatimat Motunrayo Akinlusi, ${ }^{5}$ Linda O Abegunde, ${ }^{6}$ Oladosu Ojengbede ${ }^{7}$
}

To cite: Morhason-Bello I0, Kareem YO, Abdus-Salam RA, et al. Factors associated with the awareness of vaginal fistula among women of reproductive age: findings from the 2018 Nigerian demographic health crosssectional survey. BMJ Open 2020;10:e040078. doi:10.1136/ bmjopen-2020-040078

- Prepublication history and additional material for this paper are available online. To view these files, please visit the journal online (http://dx.doi org/10.1136/bmjopen-2020040078).

Received 03 August 2020 Revised 03 August 2020 Accepted 16 October 2020

D Check for updates

(c) Author(s) (or their employer(s)) 2020. Re-use permitted under CC BY-NC. No commercial re-use. See rights and permissions. Published by BMJ.

For numbered affiliations see end of article.

\section{Correspondence to} Imran 0 Morhason-Bello; imranmorhasonbello@gmail. com

\section{ABSTRACT}

Introduction Involuntary leakage of urine and or stool per vaginam (vaginal fistula) after childbirth remains a public health challenge in Africa and South East Asia. To the best of our knowledge, there is no previous national data that examined the awareness of vaginal fistula among women in Nigeria.

Aim To determine the prevalence of awareness of urinary/faecal incontinence due to vaginal fistula, and the associated risk factors among women with no previous experience of incontinence.

Methods We used a cross-sectional study, the 2018 Nigerian Demographic Health Survey, to analyse awareness of vaginal fistula among women with no previous leakage of urine or stool. The primary outcome was childbirth experience, and other variables were demographics, access to information and reproductive or sexual history. The descriptive, univariate and multivariable models were presented.

Results of 26585 women interviewed, 50 (0.2\%) who had experienced fistula were excluded from the risk factor analysis. The mean age of women with childbirth experience was $32.8 \pm 8.6$ years, while that of women without childbirth experience was $20.3 \pm 6.2$ years. The prevalence of vaginal fistula awareness was $52.0 \%$. Factors associated with the awareness include the following: childbirth experience (adjusted $O R(A O R)=1.14$; $95 \% \mathrm{Cl}, 1.01$ to 1.30 ); age of 20-24 years (AOR=1.36; $95 \% \mathrm{Cl}, 1.18$ to 1.56 ) and older; currently working ( $\mathrm{AOR}=1.35 ; 95 \% \mathrm{Cl}, 1.22$ to 1.49) and ownership of a mobile phone (AOR=1.16; $95 \% \mathrm{Cl}, 1.05$ to 1.27 ). Other associated factors include the following: having at least secondary education; wealth quintiles, ethnicity, regional location, religion, access to radio, newspaper and internet; age up to 17 years at first sex; history of previous termination of pregnancy and use of contraception. Conclusion A significant number of young women with no childbirth experience had low level of awareness. We recommend vaginal fistula awareness programmes that will target women at risk of vaginal fistula and the inclusion of other useful questions to improve the quality of information in future surveys.

\section{Strengths and limitations of this study}

- The study used a nationally representative large data set of 26535 women of reproductive age (1549 years) to investigate factors associated with the awareness of fistula. It is possibly the largest data set analysed.

- This study provided an insight into the level of awareness of vaginal fistula, particularly, among women within the age range of highest risk.

- Given that the Demographic Health Survey has thankfully included relevant questions on awareness of incontinence of urine and stool in its data set, we identified that some useful information that could help to better understand the context of awareness or knowledge were missing.

- This analysis relied on a secondary data with the possible attendant challenges of such data.

- The number of women who had experienced vaginal fistula were small $(n=50)$ and do not allow for rigorous statistical approach except for descriptive summaries

\section{INTRODUCTION}

Urinary or faecal incontinence among women is a devastating medical morbidity that is mostly caused by prolonged obstructed labour. ${ }^{1}$ The delay in relieving the obstructed labour is usually due to lack of access to essential maternity services. ${ }^{1}$ According to Thaddeus and Maine, ${ }^{2}$ the three delay models used to describe obstetric obstacles leading to maternal death are as follows: (i) delay in decision to seek appropriate medical help for an obstetric emergency; (ii) delay in reaching an appropriate obstetric facility and (iii) delay in receiving adequate care at the facility. Indeed, Thaddeus and Maine identified recognition of danger signs as the initial step to accessing healthcare by women with 
obstetric complication, it was not established as a definite phase in the model until recently when the delay models were modified and recategorised into four levels. ${ }^{2}$ The new addition was delay in identifying the warning sign as the first level. These delays also contribute to the occurrence of severe morbidities including vaginal fistula-leading to urinary or faecal incontinence. ${ }^{3}$ Aside neglected labour, vaginal fistula could also occur from complications of gynaecological surgeries, caesarean sections, obstetric procedures, radiotherapy, gynaecological cancer and sexual assault. ${ }^{45}$

Although the exact global estimates of urinary (vesicovaginal fistula) and or faecal (recto-vaginal fistula) incontinence burden is unknown, estimates by the WHO showed that more than 2 million women are currently living with the disorder and between 80000 and 100000 new cases are detected every year, largely in sub-Saharan Africa (SSA) and South East Asia. ${ }^{6-8}$ Nigeria and Ethiopia have the highest burden of obstetric fistula in SSA. ${ }^{6}$ According to the 2008 Nigerian Demographic Health Survey (NDHS), the prevalence of urinary incontinence was $0.4 \%$, with highest prevalence in the Northern regions compared with the Southern regions. ${ }^{9}$ Evidence abound that the risk of vaginal fistula is common in settings with lack or inadequate qualitative emergency obstetric care, healthcare manpower challenges and poor investment in maternity services. ${ }^{10}$ Beyond the medical factors, sociocultural issues such as early marriage, harmful cultural practices like female genital mutilation and unsupervised childbirth at home; poor policy implementation of girl child education and misconceptions about childbirth practices are other drivers responsible for the huge burden of obstetric fistula in SSA and Southeast Asia. ${ }^{110}$

Despite the huge burden of obstetric fistula in SSA, studies addressing the awareness of obstetric fistula among women are limited, particularly in Nigeria. ${ }^{11}$ The prevalence of awareness was 20\%-61\% in Ghana, Uganda, Ethiopia and Tanzania. ${ }^{12-15}$ Generally, there are more studies that reported poor awareness level of vaginal fistula compared with those that reported high level of awareness among women. It is important to evaluate the level of awareness of women who are at risk of developing involuntary leakage of urine and or faeces, especially, in Nigeria, where the burden is high. Adequate information on the risk factors associated with vaginal fistula would help women to take appropriate decision to prevent difficult labour, the the most common cause of vaginal fistula. Furthermore, findings from this analysis will assist policy-makers and public health programmers to understand the level of awareness of vaginal fistula and the contributory factors. This study aimed to determine the prevalence of, and the factors that could contribute to the awareness of vaginal fistula among women of reproductive age in Nigeria.

\section{METHODS}

\section{Study design and data}

The study utilised data from the 2018 NDHS. Nigeria is divided into six geopolitical regions, which consists of 36 states and a federal capital territory (FCT). Each state and FCT is subdivided into local government areas (LGAs). The LGAs were further divided into localities to make up census enumeration areas (EAs). The NDHS adopted a two-stage stratified cluster sampling technique; the states and FCT were stratified into urban and rural areas. The first stage involved 1400 EAs that were selected with probability proportional to EA size across the states. While in the second stage, 30 households were selected in every EAs using equal probability sampling. Further details of sampling design, method and implementation can be found in the 2018 NDHS report. ${ }^{16}$

\section{Patient and public involvement statement}

Participants were not directly involved in the planning of the NDHS. Information was disseminated to the general public including the participants as part of the protocol for a demographic health survey.

\section{Data management \\ Outcome variables}

The data on vaginal fistula were extracted from the women's questionnaire. The fistula module in the NDHS sought information on the awareness of vagina fistula from all women of reproductive age 15-49, and information on the knowledge about the cause, health seeking behaviour including access and effective treatment were sought from only those with a complaint of fistula. Out of the 14 item questions in the fistula section, the first question asked if a woman had ever experienced a constant leakage of urine or stool from vagina during the day or night, which we defined as vaginal fistula (online Supplemental box 1). The 50 women who had experienced vaginal fistula were excluded from the analysis on vaginal fistula awareness. The question on ever heard of leakage of urine or stool per vaginam (vaginal fistula) was used as the primary outcome for this study, and as a measure of level of awareness among participants.

\section{Explanatory variables}

The explanatory variables in this analysis were categorised into three groups: demographic, access to information and reproductive and sexual history characteristics. The demographic variables included in the model were as follows: age groups (15-19, 20-24, 25-29, 30-34, 35-39, 40-44, 45-49) years; region (North Central, North East, North West, South East, South South, South West); place of residence (urban, rural); ethnicity (Fulani, Hausa, Igbo, Yoruba, other ethnic minorities); religion (Catholic, other Christians, Muslims, Traditional, others); highest educational level (no education, primary, secondary, higher) occupation (not currently working, working) and wealth quintiles (poorer, poor, middle, richer, richest). 
Information related to access to media included the following: frequency of reading newspaper or magazine (not at all, less than once a week, at least once a week); frequency of listening to radio (not at all, less than once a week, at least once a week); frequency of watching television (not at all, less than once a week, at least once a week); own a mobile phone (no, yes) and use of internet (never, in the last 12 months, before last 12 months). Other related access to information were knowledge and use of family planning: knowledge of contraceptive method (knows no method, knows only folkloric method, knows only traditional method, knows modern methods); current use of contraceptive method (no method, folkloric method, traditional method, modern method); heard family planning on radio last few months (no, yes); heard family planning on television last few months (no, yes); heard family planning on newspaper and magazine last few months (no, yes) and heard family planning by text messages on mobile phone last few months (no, yes).

The variables that were considered under reproductive and sexual history characteristics included the following: childbirth experience (no, yes); currently pregnant (no or unsure, yes) and age at first sex (not had sex, $<15$ years, $15-17$ years, $18-25$ years, $>25$ years).

\section{Data analysis}

The main primary response in this analysis was ever had a childbirth experience. The percentage distribution and a $\chi^{2}$ test of association on the background characteristics between women who had no previous childbirth experience and at least a childbirth was presented, since obstetric fistula is associated with childbirth. The mean and SD were presented for continuous variables or median and IQR if the Shapiro-Wilk test for normality has a p-value of $<0.05$. The prevalence of fistula awareness and univariate analysis were presented. The outcome variable, ever heard of fistula was a binary response (no, yes).

Four different logistic regression models were fitted. In the first model, we used childbirth experience and age of women a priori. In the second model, we adjusted for other reproductive and sexual history. In the third model we adjusted for demographic characteristics, and in the final model, we adjusted for variables related to access to information. A pairwise correlation matrix and variance inflation factor $(>5)$ were used to investigate collinearity between the outcome measure and dependent variables. ${ }^{17}$ None of the dependent variables was excluded due to collinearity. Analyses were performed with Stata V.15.0 software, at 0.05 level of significance. We also presented a descriptive summary of women who had previously experienced fistula. A geospatial visual representation showing the prevalence of fistula awareness across states in Nigeria was generated using the ArcGIS software (V.10.4).

\section{RESULTS}

There were 26585 women who responded to the questions in the fistula module. Only $50(0.2 \%)$ women reported ever having vaginal fistula and most said it occurred after a difficult delivery $(82.5 \%[33 / 40])$ and live birth $(70.0 \%$ [35/50]). Two $(4.0 \%)$ of the 50 women with history of vaginal fistula reported that their fistula was due to sexual assault. The median duration from the time of injury to leakage of urine or stool was a day with a range of 1.0-5.0 days. The median age of respondents who had experienced vaginal fistula was $16.0(15.0-20.0)$ years (table 1). Only $41(82 \%)$ out of 50 women had sought treatment for their fistula. Of the 41 treated, $27(66 \%)$ reportedly had surgical repair.

The background characteristics of participants who answered the question on vaginal fistula awareness were presented according to their childbirth experience (table 2). The mean age of women with at least one previous childbirth experience was higher than those with no childbirth experience $(32.8 \pm 8.6$ years vs $20.3 \pm 6.2$ years; $\mathrm{p}<0.001)$. There were significant differences in all the selected demographics, access to information and reproductive/sexual history variables between participants with at least one previous childbirth and those with no childbirth experience $(\mathrm{p}<0.001)$. For example, there were more adolescents (15-19 years) who had not experienced childbirth compared with those with a previous childbirth experience ( $60.4 \%$ vs $4.0 \%$; $\mathrm{p}<0.001)$. On access to information, women who owned a mobile phone were higher among women with no childbirth experience compared with those with previous childbirth ( $54.4 \%$ vs $53.0 \%$; $\mathrm{p}=0.032$ ). Regarding the reproductive and sexual history, there were more women with previous history of termination of pregnancy among those with previous childbirth relative to women with no childbirth experience $(14.3 \%$ vs $3.5 \%$; $\mathrm{p}<0.001)$.

The overall prevalence of awareness of vaginal fistula among the participants was $52.0 \%$ (13 066/26 535) (table 3 ). There was a linear trend between the prevalence of awareness of fistula and age group of participants. The prevalence of awareness of fistula was highest among women aged $45-49$ years $(55.8 \%)$ compared with other age groups. Generally, the prevalence of awareness of fistula was higher in the northern regions than the southern regions (figure 1). The awareness of fistula was highest among women in the North West $(80.2 \%)$, those living in the rural communities (59.0\%), who are Muslims $(64.5 \%)$, with no formal education $(67.7 \%)$ and from the poorest wealth quintiles $(68.4 \%)$.

Women who read newspaper at least once a week $(53.5 \%)$, never listened to radio $(55.2 \%)$, never watched television $(61.4 \%)$, never owned a mobile phone $(57.5 \%)$ and never used internet $(53.5 \%)$ had the highest proportions of those that had ever heard of fistula. The awareness of fistula was highest among women with history of termination of pregnancy $(61.8 \%)$, currently pregnant $(60.5 \%)$, had a previous childbirth $(56.6 \%)$ and never used a contraceptive method (53.7\%).

In the unadjusted analyses (table 3), the odds of ever heard of fistula by the participants was associated with demographic factors. Specifically, the odds of awareness 
Table 1 Characteristics of women (15-49 year) who had experienced Fistula in the 2018 NDHS data

\begin{tabular}{ll}
\hline Variable & Frequency (\%) \\
\hline $\begin{array}{l}\text { Age at onset of vaginal fistula symptom } \\
\text { (median, Q1-Q3) }\end{array}$ & $16(15-20)$ \\
$<15$ & $12 / 50(24.0)$ \\
$15-19$ & $23 / 50(46.0)$ \\
\hline $20-24$ & $10 / 50(20.0)$ \\
$>24$ & $5 / 50(10.0)$ \\
\hline
\end{tabular}

Time problem occur

$\begin{array}{ll}\text { After the delivery of a live baby } & 35 / 50(70.0) \\ \text { After a stillbirth } & 5 / 50(10.0) \\ \text { Neither } & 10 / 50(20.0)\end{array}$

Risk factor for vaginal fistula

\begin{tabular}{ll} 
After normal labour/delivery* & $7 / 40(17.5)$ \\
\hline After very difficult labour/delivery* & $33 / 40(82.5)$ \\
\hline Following sexual assault $\dagger$ & $2 / 10(20)$ \\
\hline Others $\dagger$ & $3 / 10(30)$ \\
Onset of vaginal fistulał (median, Q1-Q3) & $1(1-5)$ \\
\hline 0 & $7 / 45(15.5)$ \\
$1-2$ & $20 / 45(44.4)$ \\
\hline $3-4$ & $4 / 45(9.7)$ \\
$5-6$ & $4 / 45(9.7)$ \\
$\geq 7$ & $10 / 45(22.2)$ \\
Previous vaginal fistula treatment & \\
No & $9 / 50(18)$ \\
Yes & $41 / 50(82)$
\end{tabular}

Cadre of health worker that offered

treatment for vaginal fistula§

\begin{tabular}{ll} 
Doctor & $34 / 41(82.9)$ \\
\hline Nurse/midwife & $2 / 41(4.9)$ \\
\hline Community/village health worker & $2 / 41(4.9)$ \\
\hline Other & $3 / 41(7.3)$ \\
\hline Had had surgical fistula repair§ & \\
\hline No & $14 / 41(34.2)$ \\
\hline Yes & $27 / 41(65.8)$ \\
\hline Outcome of vaginal fistula repair§ & \\
\hline Yes, stopped completely & $37 / 41(90.2)$ \\
\hline Not, stopped but reduced & $3 / 41(7.3)$ \\
\hline Not stopped at all & $1 / 41(2.4)$ \\
\hline
\end{tabular}

*Asked from participants who experienced fistula from delivery complication $(n=40)$.

†Asked from participants whose fistula experience were not pregnancy related, there were five missing responses $(n=10)$. $\ddagger$ Asked from participants whose fistula experience were from delivery complication or not, there were five missing responses $(n=45)$.

§Asked from participants who sought treatment for fistula $(n=41)$. NDHS, Nigerian Demographic Health Survey.

of fistula was higher among women aged 20-24 years and older compared with those whose age was 15-19 years. Women living in the North East and North West had higher odds of ever reporting to have heard of fistula than those from North Central region. However, women in all the three Southern regions of Nigeria had lower odds of awareness of fistula relative to those in the Northern region. The odds of being aware of fistula was 1.87 times (95\% CI, 1.68 to 2.09) among women living in the rural communities compared with those in the urban communities. There was a higher odds of awareness of fistula among participants from Islamic religion $(\mathrm{OR}=2.85$; 95\% CI, 2.42 to 3.37) compared with those from Catholic faith group. However, the participants who professed traditional and other religions had a lower odds of being aware of fistula relative to those from the Catholic faith group. The odds of awareness of fistula was lower among the participants that had primary, secondary and tertiary education compared with those with no formal education. There was an inverse relationship between the odds of reporting awareness of fistula and wealth quintiles of participants. For example, women from richer $(\mathrm{OR}=0.33$; $95 \% \mathrm{CI}, 0.27$ to 0.41$)$ and richest $(\mathrm{OR}=0.37 ; 95 \% \mathrm{CI}$, 0.31 to 0.44 ) wealth quintiles had the lowest odds of being aware of fistula compared with those in the poorest wealth quintile.

The odds of having ever heard of fistula by the participants was associated with access to information factors. Generally, there was an inverse relationship between the odds of ever being aware of fistula and the frequency of reading newspaper/magazine, listening to radio, watching television, frequency of using internet and ownership of mobile phone. For example, women who reported reading newspaper at least once a week $(\mathrm{OR}=0.64 ; 95 \%$ CI, 0.57 to 0.83 ) were associated with lower odds of being aware of fistula compared with those that had never read newspaper. Concerning the reproductive/sexual history factors, women who had at least a child had $1.87(95 \%$ CI, 1.73 to 2.02) odds of being aware of fistula relative to women with no previous childbirth. There were higher odds of being aware of fistula among women who were currently pregnant $(\mathrm{OR}=1.47 ; 95 \% \mathrm{CI}, 1.33$ to 1.63$)$ relative to those who were not currently pregnant. There was also a higher odds of fistula awareness among women with history of previous termination of pregnancy $(\mathrm{OR}=1.57$, 95\% CI, 1.42 to 1.75 ) compared with those with no such experience. Women who reported history of contraceptive use were associated with the lower odds of ever been aware of fistula compared with those with those with no history of contraceptive use.

The results of the adjusted analyses were presented in the multivariable logistic regression in table 4 . The first model included childbirth experience and age of respondents: women who had had a previous childbirth experience had a higher odds $(\mathrm{OR}=1.81 ; 95 \%$ CI, 1.63 to 2.01) of awareness of fistula. Only women whose ages were between 20-24 years and 25-29 years had higher odds of reporting having heard of fistula compared with women that were less than 15-19 years. The second model adjusted for the reproductive and sexual history, all variables including the model 1 variables (which were kept a 
Table 2 The background characteristics of women of reproductive age in Nigeria

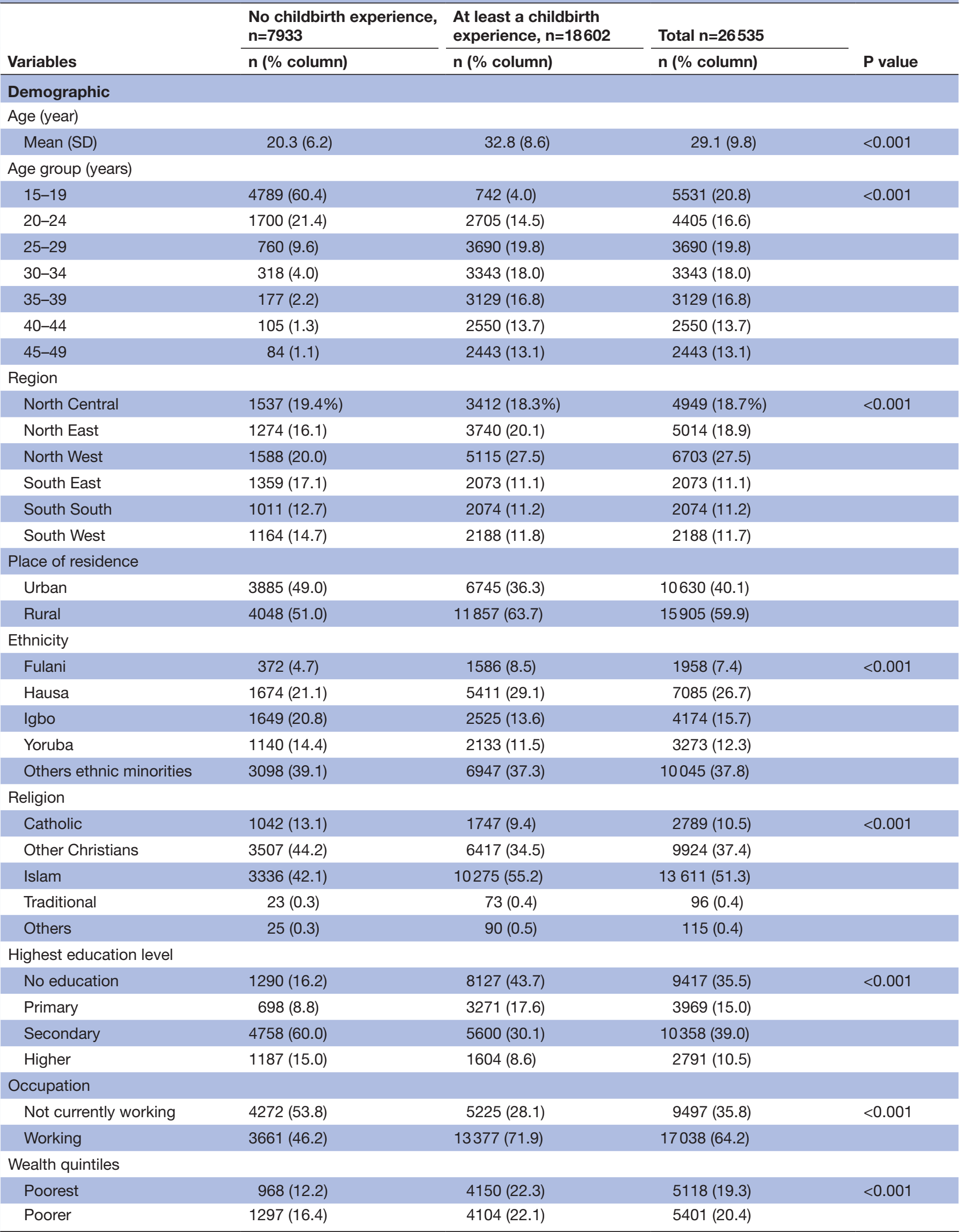


Table 2 Continued

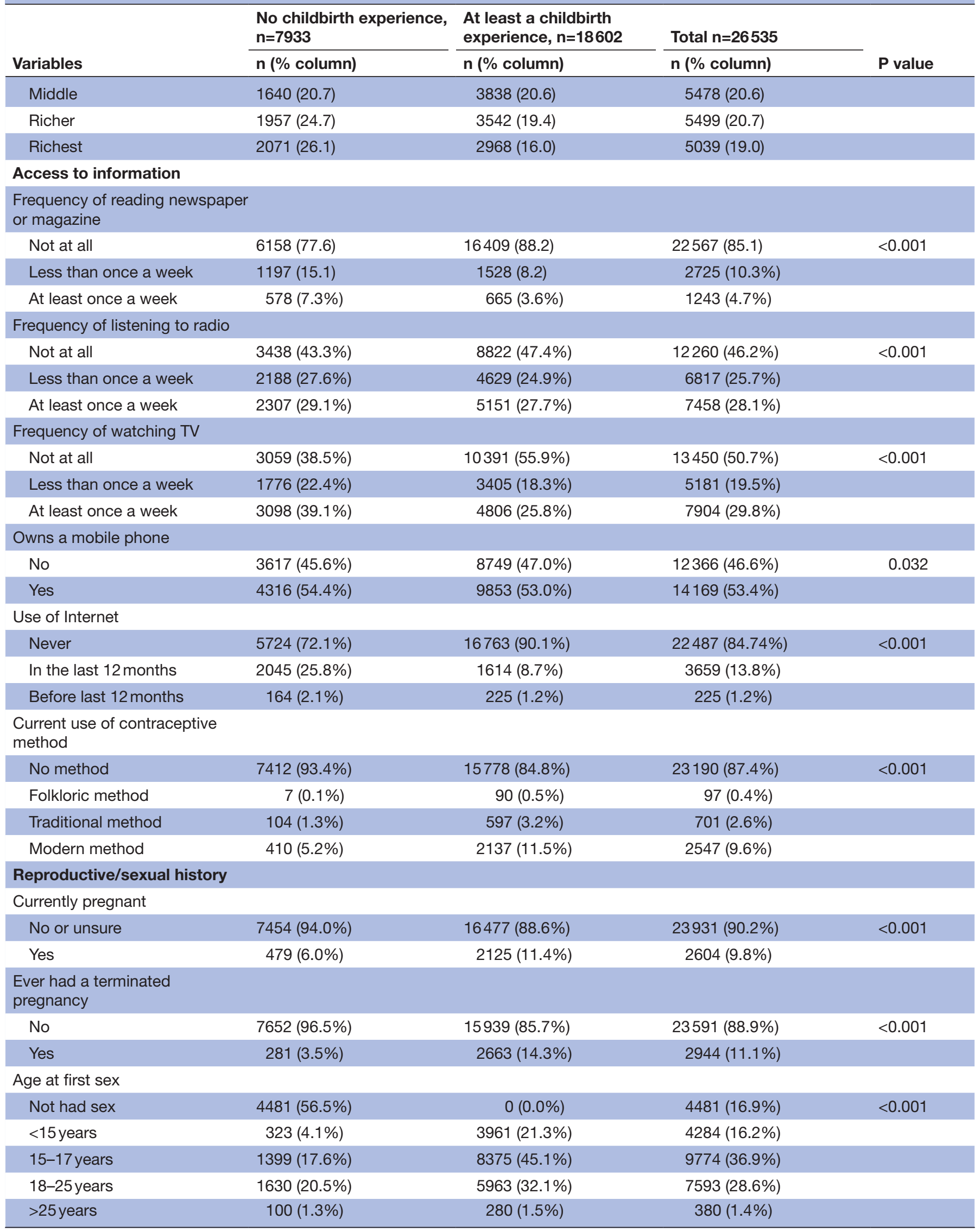


Table 3 Prevalence and bivariate analysis between explanatory variables and ever heard of fistula among women of reproductive age

\begin{tabular}{|c|c|c|c|}
\hline \multirow[b]{2}{*}{ Variable } & \multicolumn{2}{|l|}{ Ever heard of fistula } & \multirow[b]{2}{*}{$\mathrm{P}$ value } \\
\hline & Prevalence (\%; 95\% Cl) & Crude OR $(95 \% \mathrm{Cl})$ & \\
\hline \multicolumn{4}{|l|}{ Demographic } \\
\hline \multicolumn{4}{|l|}{ Age group (years) } \\
\hline $15-19$ & $41.5(39.5-43.5)$ & Reference & \\
\hline $20-24$ & $53.8(51.8-55.8)$ & $1.64(1.49-1.81)$ & $<0.001$ \\
\hline $25-29$ & $55.5(53.6-57.4)$ & $1.76(1.60-1.93)$ & $<0.001$ \\
\hline $30-34$ & $54.5(52.2-56.9)$ & $1.69(1.52-1.88)$ & $<0.001$ \\
\hline $35-39$ & $55.1(52.3-57.8)$ & $1.73(1.54-1.94)$ & $<0.001$ \\
\hline $40-44$ & $54.1(51.6-56.5)$ & $1.66(1.48-1.86)$ & $<0.001$ \\
\hline $45-49$ & $55.8(53.3-58.3)$ & $1.78(1.59-1.99)$ & $<0.001$ \\
\hline \multicolumn{4}{|l|}{ Region } \\
\hline North Central & $46.6(44.1-49.1)$ & Reference & \\
\hline North East & $61.3(58.5-64.0)$ & $1.81(1.56-2.12)$ & $<0.001$ \\
\hline North West & $80.6(78.6-82.5)$ & $4.76(4.06-5.59)$ & $<0.001$ \\
\hline South East & $27.8(24.8-30.9)$ & $0.44(0.37-0.53)$ & $<0.001$ \\
\hline South South & $35.9(33.0-39.0)$ & $0.64(0.55-0.76)$ & $<0.001$ \\
\hline South West & $22.2(19.9-24.7)$ & $0.33(0.28-0.39)$ & $<0.001$ \\
\hline \multicolumn{4}{|l|}{ Place of residence } \\
\hline Urban & $43.4(41.3-45.6)$ & Reference & \\
\hline Rural & $59.0(57.5-60.5)$ & $1.87(1.68-2.09)$ & $<0.001$ \\
\hline \multicolumn{4}{|l|}{ Ethnicity } \\
\hline Fulani & $63.7(58.6-68.5)$ & Reference & \\
\hline Hausa & $79.2(77.2-81.2)$ & $2.17(1.71-2.77)$ & $<0.001$ \\
\hline lgbo & $30.1(27.6-32.8)$ & $0.25(0.19-0.31)$ & $<0.001$ \\
\hline Yoruba & $22.5(19.9-25.2)$ & $0.16(0.13-0.21)$ & $<0.001$ \\
\hline Others ethnic minorities & $47.4(45.5-49.2)$ & $0.51(0.41-0.64)$ & $<0.001$ \\
\hline \multicolumn{4}{|l|}{ Religion } \\
\hline Catholic & $38.8(35.6-42.1)$ & Reference & \\
\hline Other Christians & $36.7(34.7-38.7)$ & $0.91(0.77-1.07)$ & 0.264 \\
\hline Islam & $64.5(62.2-66.6)$ & $2.85(2.42-3.37)$ & $<0.001$ \\
\hline Traditional & $29.5(23.6-36.2)$ & $0.66(0.47-0.92)$ & 0.015 \\
\hline Others & $3.7(1.2-11.0)$ & $0.06(0.02-0.20)$ & $<0.001$ \\
\hline \multicolumn{4}{|l|}{ Highest education level } \\
\hline No education & $67.7(65.8-69.6)$ & Reference & \\
\hline Primary & $47.0(44.4-49.7)$ & $0.42(0.54-5.09)$ & $<0.001$ \\
\hline Secondary & $38.6(36.8-40.3)$ & $0.30(0.27-0.33)$ & $<0.001$ \\
\hline Higher & $54.0(51.2-56.8)$ & $0.56(0.48-0.64)$ & $<0.001$ \\
\hline \multicolumn{4}{|l|}{ Currently working } \\
\hline No & $52.5(50.6-54.4)$ & Reference & \\
\hline Yes & $51.6(50.2-53.1)$ & $0.97(0.89-1.04)$ & 0.376 \\
\hline \multicolumn{4}{|l|}{ Wealth quintiles } \\
\hline Poorest & $68.4(65.5-71.1)$ & Reference & \\
\hline Poorer & $60.1(57.6-62.6)$ & $0.70(0.60-0.81)$ & $<0.001$ \\
\hline Middle & $48.5(46.1-50.9)$ & $0.44(0.37-0.51)$ & $<0.001$ \\
\hline
\end{tabular}


Table 3 Continued

\begin{tabular}{clll} 
& & & \\
\cline { 2 - 3 } Variable & Pver heard of fistula & & \\
\cline { 2 - 3 } Richer & $41.9(38.4-45.4)$ & $0.33(0.27-0.41)$ & $<0.001$ \\
Richest & $44.1(41.3-46.9)$ & $0.37(0.31-0.44)$ & $<0.001$
\end{tabular}

\section{Access to Information}

Frequency of reading newspaper or magazine

\begin{tabular}{llll} 
Not at all & $53.2(51.7-54.7)$ & Reference & \\
Less than once a week & $42.1(39.5-44.7)$ & $0.64(0.57-0.72)$ & $<0.001$ \\
At least once a week & $53.5(49.7-57.2)$ & $1.01(0.87-1.19)$ & 0.875 \\
Frequency of listening to radio & & & \\
Not at all & $55.2(53.3-57.1)$ & Reference & $<0.001$ \\
Less than once a week & $48.2(46.3-50.1)$ & $0.75(0.68-0.83)$ & $<0.001$ \\
At least once a week & $50.3(48.2-52.4)$ & $0.82(0.75-0.91)$ & $<0.001$ \\
\hline Fequency of watching TV & & Reference & $<0.001$ \\
Not at all & $61.4(59.7-63.1)$ & $0.46(0.41-0.51)$ & $0.48(0.42-0.55)$ \\
Less than once a week & $42.3(40.0-44.5)$ & & $<0.001$ \\
At least once a week & $43.4(40.8-45.9)$ & Reference & \\
Own a mobile phone & & $0.67(0.61-0.72)$ & \\
No & $57.5(55.8-59.2)$ & & $<0.001$ \\
Yes & $47.4(45.7-49.0)$ & Reference & $<0.001$
\end{tabular}

\section{Reproductive/sexual history}

Ever had a child

\begin{tabular}{|c|c|c|c|}
\hline No & $41.1(39.4-42.9)$ & Reference & \\
\hline Yes & $56.6(55.1-58.1)$ & $1.87(1.73-2.02)$ & $<0.001$ \\
\hline \multicolumn{4}{|l|}{ Age at first sex } \\
\hline Not had sex & $39.4(36.8-41.9)$ & Reference & \\
\hline$<15$ years & $64.1(61.8-66.3)$ & $2.75(2.41-3.15)$ & $<0.001$ \\
\hline $15-17$ years & $58.1(56.2-59.9)$ & $2.13(1.90-2.40)$ & $<0.001$ \\
\hline 18-25years & $45.3(43.5-47.1)$ & $1.28(1.15-1.42)$ & $<0.001$ \\
\hline$\geq 25$ years & $44.1(37.9-50.4)$ & $1.21(0.94-1.56)$ & 0.131 \\
\hline \multicolumn{4}{|l|}{ Currently pregnant } \\
\hline No or unsure & $51.0(49.6-52.4)$ & Reference & \\
\hline Yes & $60.5(58.0-62.8)$ & $1.47(1.33-1.63)$ & $<0.001$ \\
\hline \multicolumn{4}{|c|}{ Ever had a terminated pregnancy } \\
\hline No & $50.7(49.3-52.1)$ & Reference & \\
\hline Yes & $61.8(59.4-64.1)$ & $1.57(1.42-1.75)$ & $<0.001$ \\
\hline \multicolumn{4}{|c|}{ Current use of contraceptive method } \\
\hline No method & $53.7(52.4-55.0)$ & Reference & \\
\hline Folkloric method & $30.1(15.7-51.2)$ & $0.38(0.16-0.89)$ & 0.026 \\
\hline Traditional method & $31.3(26.9-36.0)$ & $0.39(0.32-0.48)$ & $<0.001$ \\
\hline Modern method & $43.7(40.7-46.7)$ & $0.67(0.59-0.75)$ & $<0.001$ \\
\hline
\end{tabular}




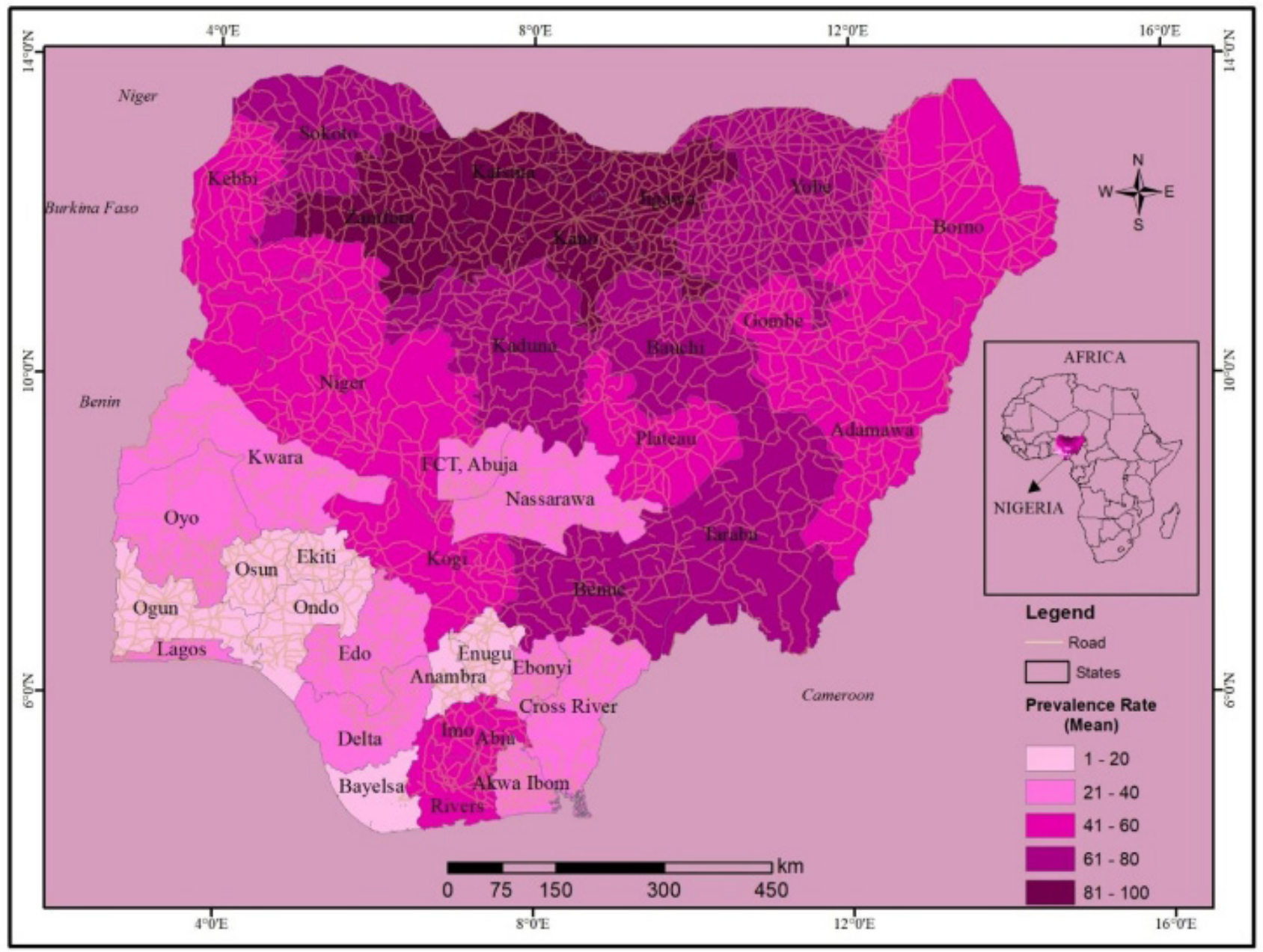

Figure 1 Prevalence of Vaginal fistula awareness by states among women of reproductive age.

priori), were statistically significant except among women that reported that their age at first sex was 25 years and older. The odds of awareness of fistula was higher among women who had their first sexual exposure at less than 15 years (adjusted OR $(\mathrm{AOR})=1.58 ; 95 \% \mathrm{CI}, 1.32$ to 1.90$)$ and between 15 and 17 years (AOR=1.30; 95\% CI, 1.11 to 1.52) compared with those who had no previous sexual exposure. However, a lower odds was observed among women aged $18-25$ years $(\mathrm{AOR}=0.81 ; 95 \% \mathrm{CI}, 0.70$ to $0.95)$ compared with women who have never had sex.

The third model included the demographic characteristics: women who were living in the southern part of Nigeria were associated with a lower odds of fistula awareness while women in the North West $(\mathrm{AOR}=3.56$; 95\% CI, 2.84 to 4.47 ) and North East (AOR $=1.82 ; 95 \%$ CI, 1.53 to 2.17) regions had higher odds compared with women in the North Central region. Similarly, women from the Yoruba (AOR $=0.47 ; 95 \% \mathrm{CI}, 0.35$ to 0.64$)$ and Igbo (AOR $=0.67 ; 95 \% \mathrm{CI}, 0.46$ to 0.98$)$ ethnic groups had a lower odds of fistula awareness. Women with secondary (AOR=1.24; $95 \%$ CI, 1.09 to 1.41$)$ and tertiary education (AOR=2.38; 95\% CI, 2.00 to 2.83) had a higher odds of fistula awareness. However, women from the poorer and middle wealth quintiles had the lower odds of been aware of fistula compared with women in the poorest wealth quintiles. The variables related with access to information that were significantly associated with the higher odds of fistula awareness included the ownership of a mobile phone (AOR=1.16; 95\% CI, 1.05 to 1.27), report of using the internet in the last 12 months $(\mathrm{AOR}=1.57$; 95\% CI, 1.33 to 1.86 ) and the history of reading newspaper or magazine at least once a week $(\mathrm{AOR}=1.29 ; 95 \%$ CI, 1.07 to 1.57 ) and listening to radio less than once a week (AOR=1.23; 95\% CI, 1.09 to 1.38$)$ relative to women without the history of these factors.

\section{DISCUSSION}

This study is probably the first largest nationally representative sample of women in SSA that investigated the level of awareness of vaginal fistula among women of reproductive age. The finding showed that only about half $(52 \%)$ of Nigerian women interviewed had ever heard of vaginal fistula. There was a high fistula awareness among young adults and those with previous childbirth experience in this study. In addition, participants 
Table 4 Multivariable logistic regression models of factors associated with the awareness of fistula among women of reproductive age

\begin{tabular}{|c|c|c|c|c|}
\hline Characteristics & $\begin{array}{l}\text { Model } 1 \\
\text { OR }(95 \% \mathrm{Cl})\end{array}$ & $\begin{array}{l}\text { Model } 2 \\
\text { AOR }(95 \% \mathrm{Cl})\end{array}$ & $\begin{array}{l}\text { Model } 3 \\
\text { AOR }(95 \% \mathrm{Cl})\end{array}$ & $\begin{array}{l}\text { Model } 4 \\
\text { AOR }(95 \% \mathrm{Cl})\end{array}$ \\
\hline \multicolumn{5}{|l|}{ Had a childbirth } \\
\hline Yes (vs No) & $1.81(1.63-2.01)$ & $1.45(1.30-1.62)$ & $1.05(0.92-1.20)$ & $1.14(1.01-1.30)$ \\
\hline \multicolumn{5}{|l|}{ Age (years) } \\
\hline $15-19$ & 1.0 (reference) & 1.0 (reference) & 1.0 (reference) & 1.0 (reference) \\
\hline $20-24$ & $1.25(1.12-1.39)$ & $1.38(1.22-1.56)$ & $1.47(1.28-1.69)$ & $1.36(1.18-1.56)$ \\
\hline 25-29 & $1.17(1.05-1.31)$ & $1.41(1.24-1.59)$ & $1.64(1.43-1.89)$ & $1.53(1.33-1.76)$ \\
\hline $30-34$ & $1.08(0.95-1.22)$ & $1.32(1.14-1.53)$ & $1.62(1.37-1.91)$ & $1.54(1.30-1.81)$ \\
\hline $35-39$ & $1.08(0.94-1.24)$ & $1.37(1.18-1.59)$ & $1.91(1.61-2.26)$ & $1.81(1.53-2.14)$ \\
\hline $40-44$ & $1.02(0.89-1.17)$ & $1.27(1.09-1.49)$ & $1.80(1.50-2.16)$ & $1.71(1.43-2.06)$ \\
\hline $45-49$ & $1.09(0.95-1.25)$ & $1.31(1.13-1.51)$ & $2.11(1.78-2.50)$ & $2.04(1.72-2.41)$ \\
\hline \multicolumn{5}{|l|}{ Age at first sex } \\
\hline Not had sex & & 1.0 (reference) & 1.0 (reference) & 1.0 (reference) \\
\hline$<15$ years & & $1.58(1.32-1.90)$ & $1.32(1.09-1.59)$ & $1.27(1.05-1.53)$ \\
\hline $15-17$ years & & $1.30(1.11-1.52)$ & $1.30(1.10-1.53)$ & $1.25(1.06-1.47)$ \\
\hline 18-25 years & & $0.81(0.70-0.95)$ & $1.19(1.00-1.42)$ & $1.14(0.96-1.35)$ \\
\hline$\geq 25$ years & & $0.78(0.59-1.03)$ & $1.02(0.74-1.41)$ & $0.95(0.69-1.32)$ \\
\hline \multicolumn{5}{|l|}{ Currently pregnant } \\
\hline Yes (vs No) & & $1.18(1.07-1.30)$ & $1.02(0.92-1.14)$ & $1.04(0.93-1.16)$ \\
\hline \multicolumn{5}{|l|}{ Had terminated pregnancy } \\
\hline Yes (vs No) & & $1.37(1.22-1.52)$ & $1.17(1.05-1.31)$ & $1.17(1.04-1.31)$ \\
\hline \multicolumn{5}{|l|}{ Use of contraceptive } \\
\hline No method & & 1.0 (reference) & 1.0 (reference) & 1.0 (reference) \\
\hline Only folkoric method & & $0.30(0.13-0.72)$ & $0.58(0.30-1.11)$ & $0.58(0.31-2.20)$ \\
\hline Only traditional method & & $0.40(0.32-0.50)$ & $0.73(0.58-0.91)$ & $0.70(0.56-0.88)$ \\
\hline Modern method & & $0.64(0.57-0.73)$ & $0.83(0.73-0.94)$ & $0.81(0.71-0.92)$ \\
\hline \multicolumn{5}{|l|}{ Region } \\
\hline North Central & & & 1.0 (reference) & 1.0 (reference) \\
\hline North East & & & $1.82(1.53-2.17)$ & $1.84(1.55-2.20)$ \\
\hline North West & & & $3.56(2.84-4.47)$ & $3.57(2.85-4.48)$ \\
\hline South East & & & $0.45(0.33-0.61)$ & $0.42(0.31-0.58)$ \\
\hline South South & & & $0.56(0.47-0.67)$ & $0.53(0.44-0.63)$ \\
\hline South West & & & $0.40(0.32-0.49)$ & $0.37(0.30-0.45)$ \\
\hline \multicolumn{5}{|l|}{ Place of residence } \\
\hline Rural (vs Urban) & & & $1.08(0.94-1.23)$ & $1.11(0.97-1.27)$ \\
\hline \multicolumn{5}{|l|}{ Educational status } \\
\hline No education & & & 1.0 (reference) & 1.0 (reference) \\
\hline Primary & & & $1.03(0.90-1.18)$ & $1.02(0.89-1.18)$ \\
\hline Secondary & & & $1.24(1.09-1.41)$ & $1.14(1.00-1.30)$ \\
\hline Higher & & & $2.38(2.00-2.83)$ & $1.74(1.45-2.08)$ \\
\hline \multicolumn{5}{|l|}{ Ethnicity } \\
\hline Fulani & & & 1.0 (reference) & 1.0 (reference) \\
\hline Hausa & & & $1.66(1.33-2.09)$ & $1.67(1.33-2.09)$ \\
\hline Igbo & & & $0.67(0.46-0.98)$ & $0.67(0.46-0.97)$ \\
\hline
\end{tabular}




\begin{tabular}{|c|c|c|c|c|}
\hline Characteristics & $\begin{array}{l}\text { Model } 1 \\
\text { OR }(95 \% \mathrm{Cl})\end{array}$ & $\begin{array}{l}\text { Model } 2 \\
\text { AOR }(95 \% \mathrm{Cl})\end{array}$ & $\begin{array}{l}\text { Model } 3 \\
\text { AOR }(95 \% \mathrm{Cl}) \\
\end{array}$ & $\begin{array}{l}\text { Model } 4 \\
\text { AOR }(95 \% \mathrm{Cl}) \\
\end{array}$ \\
\hline Yoruba & & & $0.47(0.35-0.64)$ & $0.47(0.34-0.64)$ \\
\hline Others & & & $0.83(0.64-1.06)$ & $0.84(0.65-1.08)$ \\
\hline \multicolumn{5}{|l|}{ Religion } \\
\hline Catholic & & & 1.0 (reference) & 1.0 (reference) \\
\hline Other Christian & & & $0.82(0.70-0.95)$ & $0.83(0.71-0.97)$ \\
\hline Islam & & & $0.77(0.63-0.95)$ & $0.78(0.63-0.96)$ \\
\hline Traditionalist & & & $0.22(0.12-0.43)$ & $0.24(0.12-0.46)$ \\
\hline Others & & & $0.05(0.02-0.18)$ & $0.05(0.01-0.16)$ \\
\hline \multicolumn{5}{|l|}{ Currently working } \\
\hline Yes (vs No) & & & $1.39(1.26-1.54)$ & $1.35(1.22-1.49)$ \\
\hline \multicolumn{5}{|l|}{ Wealth quintiles } \\
\hline Poorest & & & 1.0 (reference) & 1.0 (reference) \\
\hline Poorer & & & $0.82(0.71-0.95)$ & $0.81(0.70-0.93)$ \\
\hline Middle & & & $0.79(0.67-0.95)$ & $0.76(0.63-0.91)$ \\
\hline Richer & & & $0.89(0.74-1.06)$ & $0.80(0.66-0.96)$ \\
\hline Richest & & & $1.22(0.99-1.49)$ & $0.99(0.80-1.22)$ \\
\hline \multicolumn{5}{|c|}{ Read newspaper or magazine } \\
\hline Not at all & & & & 1.0 (reference) \\
\hline Less than once a week & & & & $0.93(0.82-1.06)$ \\
\hline At least once a week & & & & $1.29(1.07-1.57)$ \\
\hline \multicolumn{5}{|l|}{ Listen to radio } \\
\hline Not at all & & & & 1.0 (reference) \\
\hline Less than once a week & & & & $1.23(1.09-1.38)$ \\
\hline At least once a week & & & & $1.23(1.10-1.38)$ \\
\hline \multicolumn{5}{|l|}{ Watch TV } \\
\hline Not at all & & & & 1.0 (reference) \\
\hline Less than once a week & & & & $0.92(0.81-1.04)$ \\
\hline At least once a week & & & & $1.05(0.91-1.22)$ \\
\hline \multicolumn{5}{|l|}{ Own a mobile phone } \\
\hline Yes (vs No) & & & & $1.16(1.05-1.27)$ \\
\hline \multicolumn{5}{|l|}{ Use of Internet } \\
\hline Never & & & & 1.0 (reference) \\
\hline Last 12 months & & & & $1.57(1.33-1.86)$ \\
\hline before last 12 months & & & & $1.01(0.78-1.30)$ \\
\hline
\end{tabular}

Statistically significant variables at $p<0.05$ are shown in bold. AOR, adjusted OR.

living in the North and rural communities had higher prevalence of awareness of fistula than women in the Southern region and urban settings in Nigeria. The awareness of vaginal fistula was associated with the following factors: history of childbirth experience, aged 20-24 years and older, reported age at first sexual intercourse of up to 17 years, history of ever terminated a pregnancy, use of modern or traditional contraception, place of residence, having at least secondary education, ethnicity, wealth quintile and access to the source of information dissemination (radio, television and newspaper or magazine). The association between the history of previous childbirth and vaginal fistula awareness strengthens the role of antenatal care education, counselling and health promotion in the prevention and prompt treatment of obstructed labour and vaginal fistula. ${ }^{18}$ Other sources of information dissemination will be useful in educating other groups of women 
especially the adolescents on positive reproductive health information and behaviours.

Although the awareness level about the vaginal fistula in this study has increased compared with the 2008 NDHS report of $30.7 \%$, it is still a source of concern, particularly, among young population relative to older adults in Nigeria. ${ }^{9}$ The observed increase in the prevalence of vaginal fistula awareness in the 2018 NDHS might be due to the increased priority and investment in obstetric fistula prevention and treatment by the Government of Nigeria and development partners in the last decade. ${ }^{19}$ Vaginal fistula is more common among young people, who are usually at risk of obstructed labour due to inadequate pelvis. Pregnant adolescents often have difficulties in accessing timely obstetric emergency services should they develop obstructed labour. The reported prevalence of awareness of fistula from previous studies were mixed, majority were in the range of $20 \%-46 \%$, while a few others reported a higher figure than $52 \%$ found in this study. For example, two studies in Northern Ghana among 390 prenatal women (18-49 years) and 1982 (17-60 years) women in the community found that the awareness of fistula was $28.8 \%$ and $45.8 \%$, respectively. ${ }^{12}{ }^{20}$ However, a study (2010) in Mtwara region of Tanzania showed that $61.1 \%$ out of 334 women aged 18-49 years were aware of vaginal fistula. ${ }^{15}$ Higher prevalence $(81 \%)$ of fistula awareness was recorded in an Eritrean study after the implementation of health education and community mobilisation programme among women; this study however, included those living with fistula. ${ }^{21}$

Some of the risk factors associated with awareness of vaginal fistula in this study had been previously reported elsewhere. ${ }^{1322}$ The high level of awareness of vaginal fistula which was found to be significantly associated with the educational status, age older than 20 years, wealth quintiles and access to information dissemination platforms in this study, had also been previously reported. ${ }^{11-14} 20$ The high awareness level among women in the Northern region relative to the southern part of Nigeria and Hausa/Fulani than other ethnic groups could be due to the high burden of vaginal fistula and information diffusion from the high concentration of interventions on obstetric fistula in North and among Hausa/Fulanis. Surprisingly, women living in the rural communities were more likely to be aware of vaginal fistula compared with those in urban setting. This observation is against the general belief that women in the urban settings tend to have better awareness about health-related issues than their colleague in the rural setting. It is plausible that women living in rural setting might have experienced more cases of childbirth-related complications including obstetric fistula than those in urban setting.

The level of awareness of vaginal fistula might not necessarily translate to adequate knowledge that can help women to make appropriate decision on the prevention and access to care. There are some studies that had reported significant proportion of misconceptions on the causes or risk factors for vaginal fistula even among those that claimed to be aware of fistula. ${ }^{1322} 23$ In a qualitative study in Malawi, Changole et al interviewed women who were said to be aware of vaginal fistula on probable causes. $^{22}$ The authors reported that majority of these women associated vaginal fistula with sexually transmitted infection, witchcraft, husband's infidelity and laziness to push during labour. ${ }^{22}$ There were two other qualitative studies from Ethiopia that also showed that women including those suffering from incontinence had misconception on the probable risk factors for vaginal fistula. ${ }^{23} 24$

Another limitation of the data on awareness is the inability to disaggregate the information on subtle differences between urinary and faecal incontinence because the question was not asked separately. Other limitations include the use of secondary data and lack of information that may help to describe causes or risk factors of vaginal fistula.

It would have been beneficial if other useful information to assess the knowledge of women on urinary and faecal incontinence were collected during the 2018 NDHS It is difficult to appreciate the impact of the awareness level of vaginal fistula from the 2018 Nigerian NDHS data because of lack of other necessary information. For example, there were no questions on the sources of information and risk factors as well the preventive methods of vaginal fistula. It is imperative that future national survey consider some of the following questions with response options for participant to select: Where did you first learn or hear about involuntary leakage of urine or stool after childbirth in a woman? What did you think is/are responsible for the involuntary leakage of urine or stool after childbirth in a woman? and what are the ways of preventing the occurrence of involuntary leakage of urine or stool after childbirth in a woman? We believe that these suggested questions will add to the quality of information that will be collected to profile the public knowledge on vaginal fistula. This information will better guide the policy-makers, programme planners and experts, to design a well-informed strategy for the control of vaginal fistula in the country.

In conclusion, the study showed that a large number of women, particularly, young women with no childbirth experience and from the Southern region of Nigeria had low level of awareness of vaginal fistula. It is recommended that more public health awareness on vaginal fistula should be incorporated in reproductive health messages, especially among women of reproductive age. We also advocate that other critical questions should be included in the future national survey to help policymakers and programme planner better execute public health intervention for the control of vaginal fistula that is still ravaging Nigeria.

\section{Author affiliations}

${ }^{1}$ Department of Obstetrics and Gynaecology, Faculty of Clinical Sciences, University of Ibadan College of Medicine, Ibadan, Oyo, Nigeria

${ }^{2}$ Institute of Advanced Medical Research and Training, College of Medicine, University of Ibadan, Ibadan, Nigeria

${ }^{3}$ Centre for Population and Reproductive Health, College of Medicine, University of Ibadan, Ibadan, Oyo State, Nigeria 
${ }^{4}$ Institute of Advanced Medical Research and Training, University of Ibadan College of Medicine, Ibadan, Oyo, Nigeria

${ }^{5}$ Department of Obstetrics and Gynaecology, Lagos State University College of Medicine, Ikeja, Lagos State, Nigeria

${ }^{6}$ Cooperative Information Network (COPINE), National Space Research and Development Agency, Obafemi Awolowo University, Ile-Ife, Osun, Nigeria ${ }^{7}$ Centre for Population and Reproductive Health, University of Ibadan College of Medicine, Ibadan, Oyo, Nigeria

Acknowledgements We are grateful to DHS Program for providing access to the data.

Contributors (I) Conception and design: IOM-B and YOK; (II) data analysis: YOK and IOM-B (III) spatial data analysis: LOA; (IV) data interpretation: IOM-B, YOK, RAA-S, 00B, 00L, FMA, LOA and 00; (V) manuscript writing: all authors and (VI) final approval of manuscript: all authors.

Funding The authors have not declared a specific grant for this research from any funding agency in the public, commercial or not-for-profit sectors.

Map disclaimer The depiction of boundaries on this map does not imply the expression of any opinion whatsoever on the part of BMJ (or any member of its group) concerning the legal status of any country, territory, jurisdiction or area or of its authorities. This map is provided without any warranty of any kind, either express or implied.

Competing interests None declared.

Patient consent for publication Not required.

Ethics approval Ethical approval is not needed, the study used secondary data from the Nigeria Demography Health Surveys (NDHS). The DHS program maintain strict standards for protecting the privacy of respondents and the survey protocols are reviewed by the ICF and Institutional Review Board (IRB) in each country to ensure that the survey complies with the regulations for the protection of human subjects.

Provenance and peer review Not commissioned; externally peer reviewed.

Data availability statement Data are available in a public, open access repository. The data supporting this article is available at: https://dhsprogram.com/data/ dataset/Nigeria_Standard-DHS_2018.cfm, which can be downloaded after request from the DHS website

Supplemental material This content has been supplied by the author(s). It has not been vetted by BMJ Publishing Group Limited (BMJ) and may not have been peer-reviewed. Any opinions or recommendations discussed are solely those of the author(s) and are not endorsed by BMJ. BMJ disclaims all liability and responsibility arising from any reliance placed on the content. Where the content includes any translated material, BMJ does not warrant the accuracy and reliability of the translations (including but not limited to local regulations, clinical guidelines, terminology, drug names and drug dosages), and is not responsible for any error and/or omissions arising from translation and adaptation or otherwise.

Open access This is an open access article distributed in accordance with the Creative Commons Attribution Non Commercial (CC BY-NC 4.0) license, which permits others to distribute, remix, adapt, build upon this work noncommercially, and license their derivative works on different terms, provided the original work is properly cited, appropriate credit is given, any changes made indicated, and the use is non-commercial. See: http://creativecommons.org/ licenses/by-nc/4.0/.

\section{ORCID iD}

Imran 0 Morhason-Bello http://orcid.org/0000-0002-7448-4824
REFERENCES

1 Lufumpa E, Doos L, Lindenmeyer A. Barriers and facilitators to preventive interventions for the development of obstetric fistulas among women in sub-Saharan Africa: a systematic review. BMC Pregnancy Childbirth 2018;18:155.

2 Thaddeus S, Maine D. Too far to walk: maternal mortality in context. NewsI Womens Glob Netw Reprod Rights 1991;36:22-4.

3 MacDonald T, Jackson S, Charles M-C, et al. The fourth delay and community-driven solutions to reduce maternal mortality in rural Haiti: a community-based action research study. BMC Pregnancy Childbirth 2018;18:254.

4 Swain D, Parida SP, Jena SK, et al. Obstetric fistula: a challenge to public health. Indian J Public Health 2019;63:73-8.

5 El-Azab AS, Abolella HA, Farouk M. Update on vesicovaginal fistula: a systematic review. Arab J Urol 2019;17:61-8.

6 Tunçalp Özge, Tripathi V, Landry E, et al. Measuring the incidence and prevalence of obstetric fistula: approaches, needs and recommendations. Bull World Health Organ 2015;93:60-2.

7 Stanton C, Holtz SA, Ahmed S. Challenges in measuring obstetric fistula. Int J Gynaecol Obstet 2007;99 Suppl 1:S4-9.

8 Jokhio AH, Rizvi RM, Rizvi J, et al. Prevalence of obstetric fistula: a population-based study in rural Pakistan. BJOG 2014;121:1039-46.

9 National Population Commission (NPC) [Nigeria] and ICF. Nigeria demographic and health survey 2008. Abuja, Nigeria, and Rockville, Maryland, USA: NPC and ICF, 2009.

10 Wall LL. Obstetric vesicovaginal fistula as an international publichealth problem. Lancet 2006;368:1201-9.

11 Basheer SA, Pumpaibool T. Knowledge, attitude and maternal health care utilization among married women of reproductive age towards vesicovaginal fistula in Kebbi state, Nigeria. $J$ Health Res 2015;29:93-100.

12 Azanu WK, Dassah ET, Agbeno EK, et al. Knowledge of obstetric fistula among prenatal clinic Attendees and midwives in Mfantsiman municipality, Ghana. Int J Gynaecol Obstet 2020;148 Suppl 1:16-21.

13 Kasamba N, Kaye DK, Mbalinda SN. Community awareness about risk factors, presentation and prevention and obstetric fistula in Nabitovu village, Iganga district, Uganda. BMC Pregnancy Childbirth 2013;13:229.

14 Banke-Thomas AO, Kouraogo SF, Siribie A, et al. Knowledge of obstetric fistula prevention amongst young women in urban and rural Burkina Faso: a cross-sectional study. PLoS One 2013;8:e85921.

15 Kazaura MR, Kamazima RS, Mangi EJ. Perceived causes of obstetric fistulae from rural southern Tanzania. Afr Health Sci 2011;11:377-82.

16 National Population Commission (NPC) [Nigeria] and ICF. Nigeria demographic and health survey 2018. Abuja, Nigeria, and Rockville, Maryland, USA: NPC and ICF, 2019.

17 Joshi $\mathrm{H}$. Multicollinearity diagnostic in statistical modelling and remedies to deal with it using SAS. Pharm Users Softw Exch 2012;1:1-34.

18 Boene $\mathrm{H}$, Mocumbi S, Högberg $\mathrm{U}$, et al. Obstetric fistula in southern Mozambique: a qualitative study on women's experiences of care pregnancy, delivery and post-partum. Reprod Health 2020;17:21.

19 Amodu OC, Salami BO, Richter MS. Obstetric fistula policy in Nigeria: a critical discourse analysis. BMC Pregnancy Childbirth 2018;18:269.

20 Saeed M, Alhassan A, Opare-Asamoah K, et al. A survey on obstetric fistula awareness in northern Ghana. Eur J Exp Biol 2014;4:178-82.

21 Johnson KA, Turan JM, Hailemariam L, et al. The role of counseling for obstetric fistula patients: lessons learned from Eritrea. Patient Educ Couns 2010;80:262-5.

22 Changole J, Kafulafula U, Sundby J, et al. Community perceptions of obstetric fistula in Malawi. Cult Health Sex 2019;21:605-17.

23 Animut M, Mamo A, Abebe L, et al. "The sun keeps rising but darkness surrounds us": a qualitative exploration of the lived experiences of women with obstetric fistula in Ethiopia. BMC Womens Health 2019;19:37.

24 Gebresilase YT. A qualitative study of the experience of obstetric fistula survivors in Addis Ababa, Ethiopia. Int $J$ Womens Health 2014;6:1033. 